\title{
Do Pacto Andino à Aliança do Pacífico: reflexões sobre mecanismos da (des)integração da sub-região andina
}

\section{From the Andean Pact to the Pacific Alliance: reflections on mechanism of (dis)integration of the Andean subregion}

\author{
Ronald Clay dos Santos Ericeira* \\ https://orcid.org/0000-0003-4890-9881
}

\begin{abstract}
Resumo
A proposta deste artigo é apresentar reflexões sobre os principais mecanismos de integração e desintegração regional da região andina. Em efeito, temos dois objetivos principais, quais sejam: primeiro, empreender uma linha histórica das dinâmicas de integração sub-regional protagonizadas pelos países andinos entre 1969 e 2019; segundo, apresentar uma análise comparativa entre esses mecanismos, buscando identificar seus pontos de convergência, de divergência, as instituições criadas no âmbito da regionalização andina, bem como refletir acerca dos projetos de integração que se sucederam nessa sub-região da América do Sul ao longo das últimas décadas. Apresentaremos ainda considerações sobre a atual situação andina a partir de conceitos caros às teorias da integração regional. No tocante às fontes de dados, elas foram constituídas de material bibliográfico (artigos e capítulos de livros) e documentos oficiais disponíveis nos sites dos mecanismos de integração andina. Quanto aos resultados, alguns elementos apontam para uma possível desintegração andina: ausência de paymaster na região, forças comerciais centrífugas (Estados Unidos, União Europeia e China), sobreposição de distintos projetos de integração, divergências político-ideológicas entre os países andinos, não complementaridade e assimetria das economias dos países andinos. Eventual debilidade institucional dos mecanismos de regionalização e a busca de parceiros comerciais fora do bloco não implicam desconsiderar o esforço histórico dos países andinos pela integração regional.

Palavras-chave: região andina, integração regional, CAN, ALBA, Aliança do Pacífico.
\end{abstract}

\footnotetext{
* Doutor em Ciências Humanas (Antropologia Cultural) pela Universidade Federal do Rio de Janeiro, doutor em Psicologia Social pela Universidade Estadual do Rio de Janeiro, professor associado do Departamento de Psicologia e do Programa de Pós-Graduação em Psicologia da Universidade Federal Rural do Rio de Janeiro. E-mail: ronaldericeira@yahoo.com.br.
} 


\begin{abstract}
The purpose of this article is to present reflections on the main mechanisms of regional integration in the Andean region. In fact, we have two main objectives: firstly to undertake a historical line of the dynamics of subregional integration carried out by Andean countries between 1969 and 2019; secondly, to present a comparative analysis between these mechanisms, seeking to identify their points of convergence and divergence, the institutions created within the scope of Andean regionalization, as well as the integration projects that have succeeded in this sub-region of South America over the last few decades. We will also present considerations about the current situation of andean integration based on concepts that are dear to theories of regional integration. With regard to data sources, they consisted of bibliographic material (articles and book chapters) and official documents available on the websites of the andean integration mechanisms. As for the results, some elements point to a possible Andean disintegration: absence of paymaster in the region, centrifugal commercial forces (United States, European Union and China), overlapping of different integration projects, political and ideological differences between Andean countries, non-complementarity and asymmetry of the economies of the Andean countries. Any institutional weakness of the regionalization mechanisms and the search for commercial partners outside the bloc do not imply disregarding the Andean countries' historic efforts towards regional integration.
\end{abstract}

Keywords: andean region, regional integration, ANC, ALBA, Pacific Alliance.

\title{
Introdução
}

Os anos de 1960 marcaram a busca dos países andinos em construir um processo de integração. Nesse bojo, surgiu o Pacto Andino, que, 30 anos depois, foi substituído pela Comunidade Andina (CAN). Na contemporaneidade, a dificuldade desse bloco em dirimir os desequilíbrios econômicos e de lidar com as divergências políticas dos membros causou um overlapping regional, com a existência simultânea de distintos projetos de cooperação, que solaparam o projeto originário de integração andina. Nesse transcurso, a despeito de períodos de desentendimento e de avanços menos robustos nos processos de integração sub-regional, o crescimento do comércio intrabloco é muito maior do que o extracomunitário, tendo aumentado quase trinta 
vezes. ${ }^{1}$ Cumpre esclarecer que a questão central do artigo é analisar e como e por que um processo de integração que chegou a ser considerado o mais bem sucedido região passou a ter ao longo das décadas tantos elementos centrífugos, ao ponto de estudos voltados para esse tema sinalizar para uma eventual desintegração sub-regional. Nossa hipótese é que ausência de um paymaster, o contexto sistêmico internacional e a presença de interesses político-econômicos difusos dos estados da sub-região podem ser assinalados como fatores desagregadores da integração andina.

No tocante às fontes de dados empregadas nesse artigo, elas foram constituídas de material bibliográfico (artigos e capítulos de livros) e documentos oficiais disponíveis nos sites dos mecanismos de integração andina. Em termos de plataformas de pesquisa, recorremos sobejamente ao google scholar, scielo e banco de dissertações e tese da CAPES. Outrossim, esclarecemos que para alcançar nossos propósitos, esse artigo, além desta introdução, é composto de mais cinco tópicos. No primeiro, tratamos a integração regional como objeto de estudos das Relações Internacionais, apresentando as principais categorias analíticas e debates desse campo de estudo. No segundo, discorremos sobre aspectos históricos, institucionais e objetivos do Pacto Andino, da Comunidade Andina, da Alba e da Aliança do Pacífico. No terceiro, empreendemos uma análise comparativa desses mecanismos de integração, buscando enfatizar seus pontos de convergência, de divergência e de sobreposição. No quarto, refletimos sobres os atuais impasses de integração regional envolvendo os países andinos, apontando os possíveis fatores causais para o que autores chamam de desintegração andina. No quinto item, apresentamos as reflexões finais.

\section{O estudo da integração regional nas Relações Internacionais}

A literatura especializada das Relações Internacionais, voltada para o estudo da integração regional (IR), tem o seu nascedouro e consolidação nas práticas e nos processos acontecidos na Europa Ocidental no período após a Segunda Guerra Mundial. Chamamos a atenção para duas características dessa primeira geração de projetos de IR: a disseminação de acordos econômicos preferenciais e sua classificação com um regionalismo fechado. ${ }^{2}$ Nos

\footnotetext{
${ }^{1}$ TAMAYO, Gustavo; MARTINEZ, Elias. La comunidad andina: cohesión interna e interesses individuales de los Estados miembros. Em: Renata Peixoto de Oliveira, Silvia Garcia Nogueira, Filipe Reis Melo. (orgs) América Andina: integração regional, segurança e outros olhares, EDUEPB, 2012.

${ }^{2 \mathrm{P} E R R O T T A, ~ D a n i e l l a . ~ L a ~ i n t e g r a c i o ́ n ~ r e g i o n a l ~ c o m o ~ o b j e t o ~ d e ~ e s t u ́ d i o . ~ D e ~ l a s ~ t e o r i a s ~ t r a d i c i o n a l e s ~ a ~ l o s ~ e n f o-~}$ ques actuales. Em: Elsa Llenderrozas, Teoria de las Relaciones Internacionales, EUDEBA, 2013, p. 1- 44; FAWCETT, Louise. The History and concept of regionalism. Trabalho apresentado na Conferência Bienal "Regionalismo e Lei Internacional", Valencia, Espanha, 2012.
} 
anos de 1970 e 1980, tivemos uma segunda geração de projetos de integração regional, o “Novo Regionalismo' (NR). Este esteve relacionado sobretudo aos processos e programas de integração que aconteceram na América Latina e no Caribe. É possível apontar que o NR se caracterizou por uma dinâmica de regionalismo aberto, prevendo a possibilidade contínua de acordos bilaterais entre os membros de um bloco regional com países de fora da região. No Novo Regionalismo, apesar da preponderância de acordos econômicos e comerciais, outros temas também apareceram no horizonte de negociação, tais quais: a propriedade intelectual e compras governamentais. ${ }^{3} \mathrm{E}$ mais, paralelamente ao aprofundamento da integração comercial, nessa segunda geração de projetos de IR, houve uma profusão de acordos políticos e sociais. ${ }^{4}$ Ademais, o NR também serviu para que as Relações Internacionais estudassem diferentes modelos e graus de IR, como a formação de associações entre países de distintos continentes e hemisférios. Mais recentemente, no século XXI, houve o aparecimento do regionalismo pós-liberal ou pós-hegemônico, cujo foco de integração não é a mais a dimensão econômica, mas a cooperação social, educacional e projetos conjuntos de infraestrutura. Essa terceira onda de regionalismo foi corolário de uma crise das políticas econômicas neoliberais e das instituições multilaterais. ${ }^{5}$

No decurso das décadas, conforme apontado acima, foram inumeráveis os debates acerca da integração regional, os quais não temos a pretensão de esgotá-los. No entanto, cumpre trazer à baila alguns conceitos importantes para melhor se compreender as dinâmicas de IR. Entre eles destacamos: região, concernente tanto aos estados geograficamente próximos, quanto a países ligados por laços sociais, linguísticos ou políticos; regionalismo, relacionado às políticas e projetos de integração; regionalização, referente à integração das sociedades em dada região e aos processos de interação social e econômica; identidade regional, alusiva à percepção compartilhada de que os Estados por questões históricas, culturais ou religiosas pertencem a um mesmo escopo regional. ${ }^{6}$

Outrossim, cabe ressaltar que uma parcela significativa dos debates teórico-metodológicos da integração regional está baseada no questionamento

\footnotetext{
${ }^{3}$ PERROTTA, op.cit, p. 35; FAWCETT, op.cit, p. 66.

${ }^{4}$ SENHORAS, Eloi. A dinâmica regional nas relações internacionais, Conjuntura Global, v. 4, n.3, 2015, p. 403-423.

${ }^{5}$ SÖDERBAUM, Fredrik. Rethinking Regionalism. Palgrave MacMillan, 2016; REGGIROZZI, Pía; TUSSIÊ, Diana. "Rethinking our region in a post-hegemonic moment". In: BRICEÑO-RUIZ, José; MORALES, Isidro (orgs.). Post-hegemonic regionalism in the Americas. Toward a Pacific-Atlantic Divide? New York: Routledge, 2017.

${ }^{6}$ HURRELL, Andrew. O ressurgimento do regionalismo na Política Mundial. Contexto Internacional, Rio de Janeiro, vol. 17, n.1, 1995; PERROTA. op. cit, p. 23; FAWCETT, op.cit, p. 66.
} 
da centralidade e preponderância do modelo europeu. Diversas concepções de IR foram geradas a partir do êxito europeu após 1945 e exportadas para compreensão de outros processos de regionalismo e de regionalização. Assim, questiona-se: o arcabouço engendrado para análise da integração europeia é suficientemente abstrato e objetivo, logo aplicável a todo e qualquer contexto de integração regional? Ou é necessário produzir reflexões singulares e instrumentos analíticos específicos para cada processo de integração regional? Essa contenda reverberou também nos estudos de IR na América Latina, sobre os quais é importante fazermos breves digressões, por açambarcarem reflexões sobre os processos de integração na região andina.

Nessa perspectiva, autores defendem a existência de longa data de um "pensamento latino-americano para a integração" (PLI), que seria um conjunto de ideais e valores defendidos por intelectuais, políticos e estudiosos que compartilham uma concepção de união e de integração da América Latina. Uma das características do PLI é a constante reflexão sobre as possíveis estratégias de superação dos problemas comuns aos países da região. Todavia, os autores são cientes da dificuldade do propósito de delinear amplamente todas as dimensões do PLI. A complexidade se inicia com a própria (im)possibilidade de definição consensual da América Latina em termos geográficos, geopolíticos e epistemológicos. Acrescenta-se a isso o fato de o continente ter sido palco constante de disputas políticas (internas e com terceiros países) no decorrer de sua história, as quais inviabilizaram ou retardaram processos de integração na região.?

A despeito dessas supracitadas problemáticas, podemos identificar três pilares do Pensamento Latino-americano para Integração, a saber: autonomia, desenvolvimento e proteção de riquezas naturais. No que concerne à defesa da autonomia, estando em posição inicial de colônia e depois de periferia em relação às grandes potências, a América Latina gradualmente produziu um sentimento de independência política que veio associado à ideia de integração e de resistência a eventual recolonização: "unidos, somos mais fortes". Esta concepção soberanista/autonomista/integracionista surgiu desde a luta de independência nas proposições de integração para o Cone Sul, de Hélio Jaguaribe e de Juan Carlos Puig. ${ }^{8}$

${ }^{7}$ PAIKIN, Damián; PERROTTA, Daniella; PORCELLI, Emanual. Pensamiento latinoameicano para la integración. Crítica y Emancipación, p. 49-80,2016.

${ }^{8}$ Ibidem, p.57. 
Quanto à defesa do desenvolvimento socioeconômico do continente, esse pensamento consolidou-se com a Comissão Econômica para América Latina (CEPAL), cujas figuras proeminentes foram Raúl Prebisch e Celso Furtado. A CEPAL tinha como preocupação maior explicar o subdesenvolvimento regional, colaborar com projetos para o desenvolvimento industrial e promover a integração dos países latino-americanos. Ela defendia ser possível conseguir um desenvolvimento industrial próprio com características autonômicas para os países da América Latina a partir da construção de um mercado regional unificado. Por seu turno, a defesa dos recursos naturais como elemento importante contra a exploração das riquezas locais pelos países colonizadores/imperialistas também serviu para consolidar o discurso de unidade da América Latina. ${ }^{9}$

Do mesmo modo, é oportuno também salientar que outros pensadores advogam a existência de um pensamento integracionista singular na América Latina. Assim, reiteram que o primeiro impulso de integração no continente teve caráter político e surgiu nos movimentos independentistas do século XIX. No entanto, a partir da segunda metade do século XX, as proposições regionais de integração econômica superaram os projetos de unificação política. Em efeito, uma completa compreensão das reflexões sobre a integração na América Latina deve englobar os projetos integracionistas pré-1950, as teses da CEPAL e da escuela del Cone Sul, bem como as recentes proposições de regionalismo pós-hegemônico do século XXI. Nesses termos, a integração regional latino-americana tem uma longue durée, bem anterior, portanto, à europeia após a Segunda Guerra. ${ }^{10}$

Em que pese a América Latina per se ser um celeiro de teorias e saberes sobre sua própria regionalização, os estudos de integração regional são dominados pelas formulações conceituais criadas a partir da experiência europeia. Exatamente a discussão sobre a 'exportabilidade' das teorias europeias para o contexto latino-americano, conforme mencionado anteriormente, é uma das preocupações centrais de diversos pesquisadores do tema. Se, por um lado, em termos epistemológicos, há o reconhecimento que o modelo europeu não deve ser empregado acriticamente em outras realidades; por outro lado, é inegável a influência da integração europeia na formulação de políticas e de projetos de integração em outras regiões, inclusive na América Latina. No

\footnotetext{
${ }^{9}$ Ibidem, p. 60.

${ }^{10}$ BRICEÑO-RUIZ, José; LOMBAERDE, Philippe. Regionalismo latino-americano: produção do saber, criação e importação de teorias. Civitas, Dossiê Mundialização, regionalização e importação de teorias. Porto Alegre, 2018, p. 34-70.
} 
entanto, perfilhar a importância das teorias pautadas no modelo europeu para interpretar outras dinâmicas regionais não significa necessariamente escamotear diferenças contextuais ou menosprezar saberes e conhecimentos produzidos ontologicamente a partir de cada realidade. ${ }^{11}$ Essas digressões mais conceituais nos são úteis para refletir sobre os projetos andinos de integração, visto que alguns deles inspiraram-se em termos institucionais no modelo europeu de integração, enquanto outros mecanismos sub-regionais buscaram construir uma integração mais autônoma.

\section{O Pacto Andino}

O Pacto Andino foi regulado pelo Acordo de Cartagena em 1969. Sua composição inicial tinha os seguintes membros: Bolívia, Colômbia, Chile, Equador e Peru. Em 1973, a Venezuela assinou o protocolo de adesão; por seu turno, três anos depois, o Chile denunciou o acordo, retirando-se do Pacto Andino. ${ }^{12}$

O objetivo primordial do Pacto Andino era promover o comércio intrabloco e acelerar o desenvolvimento econômico de todos os membros. 0 esquema de integração previa várias medidas em conjunto, a saber: liberalização comercial, programas industriais setoriais compartilhados, cooperação técnica em várias áreas, tratamento uniforme a capitais estrangeiros e harmonização de políticas econômicas. É pertinente também ressaltar que os princípios norteadores desse Acordo eram: a) desenvolvimento equilibrado e harmônico da sub-região; b) distribuição equitativa dos benefícios e dos custos derivados da integração; c) tratamento preferencial à Bolívia e ao Equador, na condição de membros com menor grau de desenvolvimento relativo. ${ }^{13}$

Há duas interpretações para o Pacto Andino quanto ao seu modelo de regionalismo. Para alguns, ele fora concebido pela ótica do regionalismo fechado e inspirado no processo europeu de integração regional. Em sua gestação, havia sido inclusive estabelecido o prazo até 1980 para ser alcançada uma União Aduaneira com Tarifa Externa Comum. Em termos institucionais, o Pacto Andino previa instâncias intergovernamentais, como a "Comissão" com competência deliberativa e definidora das políticas gerais do referido Pacto e mecanismos supranacionais, como a "Junta", com função consultiva e voltada

\footnotetext{
${ }^{11}$ Ibidem, p. 56.

${ }^{12}$ PANEBIANO, Massiano; VILLELA, Ana Maria. O grupo sub-regional andino. Revista de Informação Legislativa. Brasília. n.81, jan/março, 1984, p. 1-35.

${ }^{13}$ Ibidem, p. 16.
} 
à elaboração de projetos técnicos, normas e estudos para o bom funcionamento da integração sub-regional. ${ }^{14}$ Não obstante, o Pacto Andino também pode ser entendido como um projeto de integração autonômica, baseado nas teses estruturais cepalinas, visto que previa um desenvolvimento industrial e integração intrarregional no primeiro momento e apenas posteriormente haveria uma abertura comercial extrabloco. ${ }^{15}$

Apesar da supracitada divergência conceitual e de ter acontecido a denúncia chilena ao Acordo de Cartagena em 1976, o Pacto Andino aprofundou-se gradualmente em termos institucionais e jurídicos. Em 1979, houve uma primeira reformulação significativa, instituída pelo Tratado de La Paz que criou novos órgãos, a saber: Comitê Econômico e Social, o Tribunal de Justiça Andino, o Fundo Andino de Reservas e o Parlamento Andino. ${ }^{16}$

o Comitê Econômico e Social tinha natureza corporativa com representantes de empresários e de trabalhadores da Bolívia, da Colômbia, do Equador, do Peru e da Venezuela. Por seu turno, o Tribunal de Justiça Andino, com sede em Quito, tinha caráter supranacional, sendo constituído por cinco juízes dotados de completa autonomia profissional. A tarefa desse tribunal era salvaguardar o ordenamento jurídico andino, oriundo dos acordos, dos protocolos, das decisões da "Comissão", bem como das resoluções da "Junta". Atuando de forma independente dos interesses particulares dos estados, o Tribunal tinha a capacidade de declarar o direito comunitário, de dirimir controvérsias e de interpretar a legislação andina de forma uniforme. Já o Fundo Andino de Reservas ${ }^{17}$ tinha os seguintes objetivos: fornecer créditos de curto ou de longo prazo para o equilíbrio da Balança de Pagamentos; contribuir para harmonização de políticas cambiais, monetárias e financeiras; prestar serviços bancários. ${ }^{18}$

No que tange ao Parlamento Andino (Parlandino), este passou a funcionar em 1984, inspirado no congênere europeu, visando proporcionar um caráter mais democrático às decisões tomadas no âmbito do Pacto Andino. Inicialmente, ele contava com deputados eleitos para os legislativos de seus

\footnotetext{
${ }^{14}$ PUERTAS, Jaime Acosta. La desintegración andina. Nueva Sociedad, 2006.

${ }^{15}$ BRICEÑO-RUIZ, Jose. La integración regional en América Latina y el Caribe: procesos históricos y realidad comparada. Mérica: Universidad de los Andes, 2011.

${ }^{16}$ LUCIANO, Bruno; BRESSAN, Regiane A comunidade andina no século XXI: entre bolivarianos e a Aliança do Pacífico. Anais do XXXVIII Encontro Anual da ANPOCS, 2014; PANEBIANO, Massiano; VILLELA, Ana Maria, op. cit., p. 19.

${ }^{17} \mathrm{Em} 1988$, o Fundo Andino altera suas regras de funcionamento, permitindo-lhe prestar serviços a terceiros países fora do Pacto Andino e passa a se chamar Fundo latino-americano de Reservas (FLAR).

${ }^{18}$ Ibidem, p. 25.
} 
estados origem, os quais seriam indicados para exercer atividades também no Parlandino.${ }^{19} \mathrm{O}$ objetivo ulterior era que os deputados fossem eleitos por sufrágio universal apenas para exercício de atividade no Parlamento Andino, tal qual acontece no Parlamento Europeu. O Parlandino tem agido para aprofundar a integração do bloco para além de questões econômicas e comerciais. A propósito, por sua iniciativa, em 1985, foi criada a Universidad Andina Simón Bolivar, com sede em Sucre, no Equador, objetivando a cooperação científica, acadêmica e cultural dos países andinos.

\section{A Comunidade Andina}

A crise da dívida externa que abalou as economias latino-americanas na década de 1980 e o avanço das teses neoliberais difundidas pelo Consenso de Washington tiveram impactos no processo de cooperação dos países andinos, obrigando-os a rever os desafios e os entraves para a continuidade dessa integração sub-regional. Assim, o contexto sistêmico internacional e a rejeição do adensamento de mecanismos supranacionais passaram a condicionar as decisões e interesses dos estados andinos. Com efeito, tais países passaram a ficar receosos de perda de parte da soberania estatal em matérias econômico-comerciais, bem como almejavam desburocratizar as regras do Pacto Andino, para tornar possível o estabelecimento de parcerias comerciais com países fora do bloco. Buscando contornar tais impasses político-econômicos, em 1997, Bolívia, Colômbia, Equador, Peru e Venezuela reformularam pela segunda vez a institucionalidade do Pacto Andino e, por meio da assinatura do Protocolo de Trujilo, criaram a Comunidade Andina: CAN. ${ }^{20}$

A CAN manteve os seguintes propósitos originais do Pacto Andino: reforçar a solidariedade regional, reduzir as diferenças de grau de desenvolvimento entre seus membros e estimular a cooperação econômica entre eles. No entanto, a CAN optou por um mecanismo aberto de regionalização, o que permitia acordos comerciais intrarregionais, sem inviabilizar pactos com terceiros países. Nessa tessitura de integração aberta, os membros da CAN buscaram aprofundar colaboração entre por meio de um Memorando de Entendimento com relação à Supervisão Bancária Recíproca, ratificado por Colômbia, Peru e Venezuela em 1998 e pela retomada da proposta de

\footnotetext{
${ }^{19} \mathrm{Na}$ atualidade, Bolívia, Equador e Peru avançaram no sentido de promover eleições legislativas específicas para o Parlandino. A Colômbia ainda possui deputados com dupla função parlamentar no legislativo nacional e no Parlamento Andino. Forte: http//: www.parlandino.org. Acesso em 20 de outubro de 2019.

${ }^{20}$ SILVA, José Ultemar. A importância da Comunidade Andina para a economia da América Latina. Revista Gerenciais, São Paulo, v.5, n. 2, p. 72-81, 2006.
} 
estabelecimento de uma Tarifa Alfandegária Externa Comum, que, embora imperfeita, englobaria em torno de $90 \%$ de todas as mercadorias importadas pelos seus membros. Ressaltamos que nesse transcurso o comércio intrabloco cresceu 30 vezes. Paralelamente, no âmbito das relações extrabloco, podemos destacar o significativo aumento do comércio da CAN com a União Europeia, os Estados Unidos e a China. ${ }^{21}$

Malgrado a opção pelo regionalismo aberto, a CAN manteve os órgãos de caráter supranacional criados durante a vigência do Pacto andino, ampliou o acesso popular ao processo de formulação e de implementação de políticas comunitárias, mas manteve a prioridade em mecanismos intergorvenamentais como instâncias decisórias e deliberativas. Atualmente, a Comunidade Andina é composta pelos seguintes instrumentos institucionais: Consejo Presidencial Andino (órgão máximo); Comisión de la Comunidad Andina; Consejo Andino de Ministros de Relaciones Exteriores; Parlamento Andino; Tribunal de Justicia Andina; Consejo Executivo Empresarial; Consejo Consultivo Laboral; Consejo Consultivo de Pueblos Indígenas; Consejo Consultivo de Autoridades Municipales e Secretaria Geral, que substituiu a antiga Junta do Acordo de Cartagena. ${ }^{22}$

No que tange aos diferentes órgãos institucionais da CAN, sinalizamos que o Consejo Presidencial Andino é o mais importante, tendo como principal função emitir diretrizes sobre o destino da integração sub-regional. Por seu turno, o Consejo de Ministros de Relaciones Exteriores determina a direção política a ser tomada pela CAN. Já o Parlandino e o Tribunal de Justiça Andina mantiveram as mesmas funções institucionais desde o Pacto Andino. ${ }^{23} \mathrm{Um}$ dado a acrescentar é que, em 2004, foi introduzida a cláusula democrática no interior do grupo.

É oportuno reiterar que a CAN, em um processo de spill over, além da integração econômica entre os estados-membros que era o foco do Pacto Andino, também buscou ampliar a colaboração em outros âmbitos, como o desenvolvimento sociocomunitário por meio do Convênio Simón Rodríguez, cujos objetivos são: a) debater iniciativas para melhorar a qualidade de vida social nos países membros; b) fomentar políticas de emprego, capacitação profissional, seguridade social; c) propor ações de cooperação e coordenação entre os países-membros em temáticas sociais e laborais. ${ }^{24}$ Do mesmo

\footnotetext{
${ }^{21}$ TAMAYO, Gustavo; MARTINEZ, Elias David, op cit., p. 23.

${ }^{22}$ SILVA, op. cit., p. 77.

${ }^{23}$ MORA, Luis Beltran. Comunidad Andina y negócios internacionales: uma visión desde su institucionalidad y supranacionalidad. Revista Escuela de Administración de Negocios, 75, p.70-85, 2013.

${ }^{24}$ Fonte: http//: www.sela.org. Acesso em 25 de outubro de 2019.
} 
modo, cabe também frisar que, seguindo o modelo europeu de integração, em 2001, os membros da CAN instituíram o passaporte andino, como forma de impulsionar a criação de uma cidadania andina. O objetivo maior era criar um documento supranacional, para facilitar a circulação dos seus cidadãos nacionais entre os países andinos.

Apesar do avanço em mecanismos institucionais, ao longo das primeiras décadas do século XXI, a CAN se viu incapaz de continuar promovendo o desenvolvimento econômico de seus membros, além de se mostrar ineficaz em dar respostas contundentes a graves problemas sociais da sub-região: pobreza, desigualdade, desemprego e violência. Em vista dessa dificuldade da CAN em resolver problemas socioeconômicos preeminentes na sub-região, alguns de seus membros buscaram autonomamente a realizar acordos bilaterais extrabloco, como as negociações do Peru e da Colômbia com os Estados Unidos e a União Europeia, as quais, por sua vez, foram usadas como motivos para a saída da Venezuela da CAN em 2006. ${ }^{25}$

Em razão dessa divergência no interior da CAN, a literatura aponta que os países andinos ficaram divididos entre três possibilidades mais evidentes de integração: prosseguir com a CAN ou optar por dois caminhos opostos entre si, isto é, filiar-se à ALBA ou à Aliança do Pacífico. ${ }^{26}$ Estes dois últimos blocos, embora não tenham propósitos de integração circunscritos à integração andina, elas foram incluídas em nossas análises por diversos motivos, entre os quais destacamos: ser constituída em sua maioria por países da região andina e suas existências podem ser apontadas como um fator desestabilizador da CAN per se. Aliás, a coexistência da CAN, de ALBA e da Aliança do Pacífico, desvela um fenômeno de overlapping, visto que os países dessa sub-região participaram simultaneamente de mais de mais de um desses supracitados blocos, sobrepondo, assim, seus mandatos e suas afiliações. ${ }^{27}$

\section{A Aliança Bolivariana (ALBA)}

Os processos de integração dentro da América do Sul na década de 2000, incluídos logicamente os da integração andina, apontam para um

\footnotetext{
${ }^{25} \mathrm{GAL}$, Paulo Henrique. Comunidade Andina de Nações e Aliança do Pacífico: modelos de integração regional. R.INDÉ de Ciências e Humanidade, São Bernardo do Campo, v.2, 2019, p.70-85.

${ }^{26}$ LUCIANO, Bruno; BRESSAN, Regiane, op. cit., 27.

${ }^{27}$ MARIANO, Karina Lilia; RIBEIRO, Clarissa. A Pluralidade institucional como ferramenta política na Américado Sul: sobreposição organizacionais e fragmentação regional. Revista Tempo do Mundo, IPEA, n. 23, 2020, p. 35-60.
} 
desencantamento de vários países como as medidas neoliberais dos anos precedentes. Nesse transcurso, houve uma guinada em vários países da região para governos de esquerda ou centro-esquerda. Este movimento político foi nomeado pela literatura acadêmica de 'onda rosa', com a eleição de vários presidentes, que propuseram, entre outras coisas, uma agenda pós-liberal mais progressista de integração. Entre estes líderes eleitos, podemos citar: Lula da Silva (Brasil); Nestor Kirchner (Argentina); Evo Morales (Bolívia); Hugo Chávez (Venezuela); Rafael Correa (Equador) e Michelle Bachelet (Chile). ${ }^{28}$

Essa profusão de governos progressistas possibilitou o surgimento de uma roposta de regionalismo pós-liberal no hemisfério, visando ultrapassar cooperações restritas à esfera comercial e priorizando temas como: desenvolvimento, equidade social, superação da pobreza e das assimetrias estruturais entre os países. Essa agenda integrativa concedia espaços para o ressurgimento de políticas nacionais desenvolvimentistas, mas condicionava pari passu o avanço dos projetos de integração regional à convergência ideológica dos países membros. ${ }^{29}$

No âmbito andino, nesse período em específico, Colômbia e Peru tinham governos de centro-direita, enquanto os demais haviam mergulhado na 'onda rosa'. Essa divergência ideológica no interior da CAN foi um elemento determinante da crise pela qual passou esse bloco na primeira década do século XXI. Essa polarização política impulsionou o surgimento de novos projetos de integração sub-regional, como a ALBA, Aliança Bolivariana para os povos da Nossa América e a Aliança do Pacífico, ${ }^{30}$ que incluiu os seguintes países da região andina: Bolívia, Equador e Venezuela.

A ALBA, criada em 2004, foi pautada nos princípios do regionalismo pós-liberal e na crítica ao Consenso de Washington. Essa instituição sustentava os seguintes eixos norteadores: solidariedade, formação integral e intensiva do capital humano. Além disso, foi proposta a criação de mecanismos cooperativos para diminuir a assimetria entre seus membros, como: o planejamento de uma moeda única o SUCRE (Sistema de Compensação Único Regional) e a empresa Petrocaribe. Esta deveria contribuir para a integração dos transportes

\footnotetext{
${ }^{28}$ LUCIANO, Bruno; BRESSAN, Regiane, op.cit, p. 16; STEFANONI, Pablo. Posneoliberalismo cuesta arriba. Los modelos de Venezuela, Bolívia y Ecuador en debate. Nueva Sociedad, Buenos Aires, n. 239, maio-junho, 2012, Disponível em: http//: www.nuso.org.br. Acesso em 22 de outubro de 2019.

${ }^{29}$ VEIGA, Pedro Mario; RíOS, Sandra. O regionalismo pós-liberal, na América do Sul: origens, iniciativas e dilemas. Series CEPAL/Julho, 2007, p.7-47.

${ }^{30}$ LUCIANO, Bruno; BRESSAN, Regiane, op.cit, p. 18; HERNÁNDEZ, Lorena. Evolución Institucional del Mercosur: construcción de capacidades regionales? Anais do XVI Congresso Internacional Fomerco, Salvador, Brasil, 2017.
} 
e da segurança energética da região por meio de uma política de preços subsidiados do petróleo venezuelano aos demais países da aliança. Vale também acrescentar que a ALBA pressupunha cooperação em matéria educacional e científica, como a ida de estudantes e médicos bolivianos e venezuelanos à Cuba, para capacitação profissional. Ademais, a ALBA pretendia criar seus próprios dispositivos de comunicação com canais de televisão e de rádios autônomos, quais sejam: a Telesur e a Radio sur. ${ }^{31}$

Malgrado os dois principais idealizadores da ALBA tenha sido Cuba e Venezuela, esta efetivamente se propôs a ser seu paymaster.32 0 país, que vivia um período de euforia em sua economia em razão do aumento do preço do petróleo no mercado internacional que era seu principal produto na pauta de exportação, aceitou liderar e a arcar com os maiores custos dessa proposta de integração. Assim, paralelamente ao crescimento econômico, Hugo Chávez ambicionava projetar o país como uma das principais potências regionais. ${ }^{33}$

A ALBA, tendo tido a liderança venezuelana, configurou-se como uma singularidade em relação aos demais projetos de integração regional da América Latina até então, visto reforçar o papel do Estado como condutor das políticas econômicas e propor a nacionalização de empresas transnacionais responsáveis por setores estratégicos nesses países, como o energético. Para tentar levar a cabo os supracitados projetos foram projetados seis dispositivos intergovernamentais: Consejo Presidencial, Consejo Político, Consejo Ministerial del Área Social, Consejo Ministerial de Complementación Económica, Consejo de Defensa y Consejo de Movimientos Sociales.34 No entanto, a morte de Hugo Chávez e a grave crise político-econômica na Venezuela esmaeceram a proposta de integração pós-liberal da ALBA, que foi paulatinamente se esvaziando em propósitos e em número de membros.

\section{A Aliança do Pacífico}

A Aliança do Pacífico, fundada em 2012, é composta por Chile, Colômbia, Peru e México. Esse mecanismo de integração retoma o foco econômico do

\footnotetext{
${ }^{31}$ MELO, Filipe Reis. ALBA-TCP. Un nuevo regionalismo lo más de lo mismo? In: OLIVEIRA, Renata; NOGUEIRA, Silvia; MELO, Filipe Reis. América Andina: integração regional, segurança e outros olhares. Campina Grande-PB: EDUEPB, 2012.

${ }^{32}$ MATTLI, Walter. The logic of regional integration: Europe and beyond. Cambridge University, 1999; MARIANO, Marcelo. A política externa brasileira e a integração regional: uma análise a partir do Mercosul. São Paulo: Editora Unesp, 2015.

${ }^{33}$ LUCIANO, Bruno; BRESSAN, Regiane, op.cit., p. 20.

${ }^{34}$ MELO, Filipe Reis, op. cit., p. 27.
} 
regionalismo aberto e do neoliberalismo. Sua proposta é avançar progressivamente em relação à livre circulação de bens, serviços e pessoas entre os membros, sem incluir dispositivos macroeconômicos supranacionais ou impedimentos burocráticos demasiados que possam emperrar a negociação isolada de seus membros com terceiros países. Em outras palavras, a Aliança do Pacífico pauta-se na liberalização comercial entre os seus integrantes, sem criar entraves institucionais para assinaturas de tratados de livre comércio com outros parceiros internacionais, principalmente os localizados no leste asiático. ${ }^{35}$

A Aliança do Pacífico, focando na cooperação e a integração do comercial entre os países membros e concomitantemente incentivando acordos com países do leste asiático, como a China, Japão e Singapura, desloca a ênfase nos tratados comerciais com os Estados Unidos e a Europa, que historicamente marcaram os projetos sul-americanos. ${ }^{36}$

Cabe acrescentar que a Aliança do Pacífico não tem personalidade jurídica internacional, logo nenhum acordo pode ser fechado em nome do bloco. Aliás, reiteramos, cada Estado tem a liberdade para negociar acordos comerciais unilaterais. Não obstante, para incentivar a integração econômica interna, entrou em vigor em 2016 o Protocolo Adicional do Acordo Marco, estabelecendo uma zona de livre comércio intrabloco, eliminando 92\% das tarifas dos produtos comercializados entre os membros e estabelecendo o prazo de até dez anos para os demais produtos, como o açúcar, entrassem na mesma condição alfandegária. Ademais, a Aliança do Pacífico suspendeu a exigência de vistos para os cidadãos nacionais circularem entre os países do bloco e abriu representações diplomáticas unificadas em alguns países. ${ }^{37}$

\section{Comparando os diferentes modelos de integração na sub-região andina}

Doravante, empreenderemos uma análise sincrônica entre os diferentes momentos dos projetos de integração envolvendo os países andinos, comparando os países membros, os modelos pretendidos de regionalismo, os objetivos almejados, bem como os mecanismos supranacionais e

\footnotetext{
${ }^{35}$ LUCIANO, Bruno; BRESSAN, Regiane, op.cit., p. 14.

${ }^{36}$ GIARDINI, Gian Luca. The added value of The Pacific Alliance and modula regionalism in Latin America, LSE, International Affairs, 25 de junho de 2013, Disponível em http://tinyurl.com/y7vbo27h. Acesso em 20 de setembro 2019; PATRICIO, Ricardo (2014). América Latina frente à Globalização e à crise Econômica Global: a dispersão das respostas. In; SOUSA, Lara. (Coordenação). Crise, Estado e Segurança. Lisboa, MGI Editor, p. 271-294; HERNANDEZ, op.cit., 2017, p. 12.
}

${ }^{37}$ GAL, Pedro Henrique, op.cit., p.70. 
intergovernamentais criados. Para este propósito comparativo, elaboramos os seguintes quadros analíticos: países membros; tipos de regionalismo; objetivos dos projetos de integração; órgãos e dispositivos supranacionais e órgãos e mecanismos intergovernamentais.

Quadro 1: Países membros

\begin{tabular}{|c|c|c|c|c|}
\hline Países & Pacto Andino & CAN & ALBA & $\begin{array}{c}\text { Aliança do } \\
\text { Pać́fico }\end{array}$ \\
\hline Bolívia & $\mathrm{X}$ & $\mathrm{X}$ & $\mathrm{X}$ & \\
\hline Chile & $\mathrm{X}$ (Até 1976) & & & $\mathrm{X}$ \\
\hline Colômbia & $\mathrm{X}$ & $\mathrm{X}$ & & $\mathrm{X}$ \\
\hline Equador & $\mathrm{X}$ & $\mathrm{X}$ & $\mathrm{X}$ & $\begin{array}{c}\text { Em processo } \\
\text { de Ingresso }\end{array}$ \\
\hline Peru & $\mathrm{X}$ & $\mathrm{X}$ & & $\mathrm{X}$ \\
\hline Venezuela & $\begin{array}{c}\mathrm{X}(\text { membro desde } \\
1973)\end{array}$ & $\mathrm{X}$ (Até 2006) & $\mathrm{X}$ & \\
\hline México (país não andino) & & & & $\mathrm{X}$ \\
\hline
\end{tabular}

Criação do Autor

Pelo quadro acima, é possível perceber que as mais longas participações nos processos de integração andina cabem a Bolívia, Equador, Peru e Colômbia. Entre esses quatro, os dois últimos possuem as duas maiores economias e têm a longo prazo demonstrado amplo interesse pela integração sub-regional. Os dois apenas se recusaram participar da iniciativa chavista de criação da Alba. Por seu turno, o Equador, como país minoritário em termos econômicos, esteve a reboque dos países maiores, integrando inclusive a ALBA e solicitando ingresso na Aliança do Pacífico. No que concerne à participação do Chile e da Venezuela, eles apresentam posicionamento opostos quanto à integração andina. 0 primeiro se retirou do bloco quando se iniciava o debate sobre o processo de aprofundamento dos mecanismos institucionais, optando por sua autonomia comercial. 0 país apenas retoma maior interesse em cooperar com demais países andinos, quando se propuseram a criar um mecanismo menos burocrático e normativo, que é a Aliança do Pacífico. Em direção contrária à chilena, a Venezuela, embora não seja membro fundador do Pacto Andino, participou da maior parte do processo de institucionalização da integração andina com a criação de órgãos supranacionais e intergovernamentais. O país somente se afastou da CAN, como já sinalizado, quando na sua visão, Colômbia 
e Peru tomaram medidas unilaterais de estabelecimento de acordo com os Estados Unidos e da União Europeia, em detrimento dos interesses do bloco em sua totalidade.

Quadro 2: Tipos de Regionalismos

\begin{tabular}{|c|c|c|c|}
\hline & $\begin{array}{c}\text { Regionalismo } \\
\text { Fechado/ } \\
\text { Autônomico }\end{array}$ & $\begin{array}{c}\text { Regionalismo } \\
\text { Aberto }\end{array}$ & $\begin{array}{c}\text { Regionalismo } \\
\text { Pós-liberal }\end{array}$ \\
\hline Pacto Andino & $\mathrm{X}$ & $\mathrm{X}$ & \\
\hline CAN & & $\mathrm{X}$ & \\
\hline ALBA & & $\mathrm{X}$ & \\
\hline Aliança do Pacífico & &
\end{tabular}

Criação do Autor

No trato dos tipos de regionalismos existentes no âmbito andino, é possível sinalizar que essa integração sub-regional acompanhou de forma paralela os modelos de cooperação a nível mundial. Assim, nos anos de 1960, o Pacto Andino priorizou fortalecimento do comércio entre seus membros. Para alguns autores, tratava-se de um regionalismo fechado; para outros pensadores, porém, predominou um modelo cepalino de regionalismo. Na década de 1990, no auge do Consenso de Washington e da proposta de criação da ALCA pelos Estados Unidos, os países andinos optaram por um regionalismo aberto, possibilitando, ao mesmo tempo, o fortalecimento intrarregional, mas sem criar impedimentos para o comércio com terceiros países. Nessa conjuntura, foi criada a CAN em substituição ao Pacto Andino. No século XXI, houve uma bifurcação ideológica intrabloco em termos do entendimento sobre qual tipo de regionalismo seguir. Colômbia e Peru preferiram manter o regionalismo aberto, enquanto Bolívia e Venezuela empreenderam um regionalismo pós-liberal por meio da ALBA, que açambarcaria cooperação no âmbito científico, educacional, social, médico, mas também previa um cronograma progressivo de retiradas de tarifas alfandegárias entre os países membros. No entanto, os países da ALBA estavam livres também negociar acordos de cooperação bilaterais ou multilaterais, conforme suas necessidades e interesses. ${ }^{38}$

${ }^{38}$ MELO, Filipe Reis, op.cit., p. 27. 
Quadro 3: Objetivos dos projetos de integração

\begin{tabular}{|c|c|c|c|c|}
\hline & Pacto Andino & CAN & ALBA & Aliança do Pacífico \\
\hline Liberalização comercial & $\mathrm{X}$ & $\mathrm{X}$ & & $\mathrm{X}$ \\
\hline Colaboração técnica & $\mathrm{X}$ & $\mathrm{X}$ & $\mathrm{X}$ & \\
\hline $\begin{array}{c}\text { Coordenação de Políticas } \\
\text { Macroeconômicas }\end{array}$ & $\mathrm{X}$ & $\mathbf{X}$ & & \\
\hline $\begin{array}{c}\text { Desenvolvimento com } \\
\text { diminuição de assimetrias } \\
\text { econômicas }\end{array}$ & $\mathrm{X}$ & $\mathrm{X}$ & $\mathrm{X}$ & \\
\hline $\begin{array}{c}\text { Parcerias com terceiros } \\
\text { países }\end{array}$ & $\mathrm{X}$ & $\mathrm{X}$ & $\mathrm{X}$ \\
\hline $\begin{array}{c}\text { Infraestrutura sub-regional } \\
\text { e investimento no capital } \\
\text { humano }\end{array}$ & $\mathrm{X}$ & $\mathrm{X}$ & $\mathrm{X}$ & $\mathrm{X}$ \\
\hline Tarifa Alfandegária Comum & $\mathrm{X}$ & $\mathrm{X}$ & $\mathrm{X}$ & \\
\hline $\begin{array}{c}\text { Cooperação acadêmica e } \\
\text { científica }\end{array}$ & $\mathrm{X}$ & \\
\hline
\end{tabular}

Criação do Autor

Pautando-nos em elementos materiais contidos nos tratados relacionados com a integração andina, notamos que a Aliança do Pacífico tem a pauta comercial como prioridade de sua proposta, além de liberalizar acordos unilaterais com terceiros países. A CAN, assim como o Pacto Andino no passado, visa tanto a maior colaboração econômica quanto a cooperação técnica e diminuição de assimetrias entre os membros. Além disso, a criação de uma área de livre comércio entre os membros, com redução ou eliminação total de tarifas alfandegárias, foi um projeto almejado pelo Pacto Andino e atualmente é defendido pela CAN e pela Aliança do Pacífico. A ALBA priorizava o desenvolvimento social e o humano de forma coletiva, bem como almejava melhoria do bem-estar dos países em seu conjunto. Em efeito, a ALBA tinha um vasto leque de áreas, nas quais planejava ações coordenadas dos países: política pública, comunicação, ciência, recursos hidráulicos, infraestrutura, petróleo, educação. ${ }^{39}$

${ }^{39}$ Ibidem, p. 28. 
Quadro 4: Órgão e dispositivos supranacionais

\begin{tabular}{|c|c|c|c|c|}
\hline & Pacto Andino & CAN & ALBA & Aliança do Pacífico \\
\hline Junta Andina & X & & & \\
\hline Parlandino & X & X & & \\
\hline Tribunal de Justiça Andino & X & X & & \\
\hline Comitê Econômico e Social & X & & & \\
\hline $\begin{array}{c}\text { Comisión de la Comunidad } \\
\text { Andina }\end{array}$ & & X & & \\
\hline $\begin{array}{c}\text { Consejo Executivo } \\
\text { Empresarial e laboral }\end{array}$ & & X & & \\
\hline $\begin{array}{c}\text { Consejo Consultivo } \\
\text { de Pueblos Indígenas }\end{array}$ & & X & & \\
\hline $\begin{array}{c}\text { Consejo consultivo de } \\
\text { autoridades municipales }\end{array}$ & & & & \\
\hline Passaporte andino & & & Intenção & \\
\hline $\begin{array}{c}\text { Representações } \\
\text { diplomáticas unificadas }\end{array}$ & & & \\
\hline $\begin{array}{c}\text { Moeda Única } \\
\text { Empresas superestatais } \\
\text { (comunição e petróleo) }\end{array}$ & & & \\
\hline
\end{tabular}

Criação do Autor

Quadro 5: Órgãos e mecanismos intergovernamentais

\begin{tabular}{|c|c|c|c|c|}
\hline & Pacto Andino & CAN & ALBA & Aliança do Pacífico \\
\hline Comissão Andina & $\mathrm{X}$ & & & \\
\hline Consejo Presidencial & & $\mathrm{X}$ & $\mathrm{X}$ & \\
\hline $\begin{array}{c}\text { Consejo Andino de Ministro } \\
\text { de Relações Exteriores }\end{array}$ & & $\mathrm{X}$ & $\mathrm{X}$ & \\
\hline Cúpulas Presidenciais & & & & $\mathrm{X}$ \\
\hline Conselhos Sociais & & & $\mathrm{X}$ & \\
\hline
\end{tabular}

Criação do autor

Esses dois últimos quadros corroboram o que é apontado pela maior parte da literatura acadêmica sobre o Pacto Andino e à CAN no que alude à inspiração no modelo europeu de integração com a presença de órgãos 
supranacionais e intergovernamentais. ${ }^{40}$ Aliás, somente a CAN, que substituiu o Pacto Andino, dispõe de efetivos órgãos supranacionais. Nesses dois casos, cabe destacar, porém, que os principais órgãos deliberativos são de ordem intergovernamental, compostos por representantes dos poderes executivos de cada país: Consejo de Ministro de Relaciones Exteriores e Consejo presidencial. Os órgãos supranacionais mais relevantes da CAN são: o Parlandino (legislativo) e o Tribunal de Justiça (judiciário). A Aliança do Pacífico, por seu turno, prioriza a ausência de entraves burocráticos, logo não pretende empreender órgãos ou iniciativas supranacionais, enquanto as propostas de uma moeda única e de uma empresa supranacional da ALBA não lograram sair do patamar das boas intenções.

\section{Os desafios e impasses atuais da (des) integração andina}

A reflexão acerca dos avanços, paralisações e tensões nos projetos de integração andina pode ser fundamentada em diversos níveis: sistêmico, econômico, político e institucionais. No âmbito sistêmico, cumpre relembrar que todos os processos de integração nos níveis hemisféricos e sub-regionais nas Américas, na primeira década do século XXI, foram influenciados por fatores externos ao continente como o ataque de 11 de setembro nos Estados Unidos e ao surgimento da China como potência global e demandante de commodities dos países em desenvolvimento. ${ }^{41}$ No caso específico dos países andinos, essa fase histórica já foi classificada como desintegração andina. ${ }^{42}$ Isso porque as relações específicas dos principais países da CAN com os Estados Unidos trouxeram vários impasses à integração sub-regional, colocando-se mesmo em xeque sua continuidade política e institucional. Assim, ao mesmo tempo em que se acirravam as tensões e os desentendimentos entre Caracas e Washington, Lima e Bogotá assinavam acordos econômicos bilaterais com os Estados Unidos.

Em efeito, os Estados Unidos, desde a década de 1990, funcionaram como uma espécie de força centrífuga sobre o processo de integração andina. Os tratados bilaterais de livre comércio (TLC) firmados pelas duas principais economias da CAN com os Estados Unidos minaram qualquer possibilidade

\footnotetext{
${ }^{40}$ SILVA, op. cit, p. 77; MORA, Luis Beltran, op. cit., 77; LUCIANO, Bruno; BRESSAN, Regiane, op.cit, p. 14; ESPINOSA, Maria. Mercedes. La Comunidad Andina: las fuerzas centrífugas ejercidas por los Estados Unidos sobre un régimen comercial en formación. Desafios, 30, 135-172, 2018.

${ }^{41}$ POSE, Nicolás; BIZZOZERO, Lincoln. Regionalismo, Economía Política y Geopolítica: tensiones y desafios en la nueva búsqueda de inserción internacional del Mercosur, Revista Uruguaya de Ciência Política, 28, 2019. 42. PUERTAS, Jaime Acosta, op. cit., p. 23.
} 
de prosseguimento de uma política de integração pautada em uma Tarifa Externa Comum. Mais recentemente a região da Ásia-Pacífico, sobejamente, a China, tornou-me mais uma força centrífuga, agindo para desintegrar os avanços na cooperação intrabloco entre os países andinos. ${ }^{43}$

No nível econômico, a despeito de possíveis elementos externos ao aprofundamento da integração andina, cumpre dizer que o comércio intrarregional, desde o surgimento do Pacto Andino em 1969, aumentou de US\$ 300 milhões, para US\$ 8 bilhões em 2005, enquanto os investimentos diretos dentro do blogo superaram a média de US $\$ 1$ bilhão de dólares anuais entre 2000 e 2012. Esse comércio interno ganhou novo impulso com a Aliança do Pacífico. ${ }^{44}$ No entanto, as históricas assimetrias econômicas entre os países andinos não foram até então equacionadas. Além disso, o fato de os países terem características econômicas similares e não complementares com ênfase em produtos primários e uma indústria doméstica de manufaturados não competitiva instiga mais a competição do que a cooperação entre eles, principalmente na busca de mercados externos para seus produtos agropecuários. ${ }^{45}$

No nível político, chamamos a atenção para as divergências internas entre os membros da Comunidade Andina foram se adensando ao longo da década de 2000, em razão da afiliação político-ideológica contrária dos chefes dos executivos nacionais e também devido à postura antagônica dos países da CAN em relação aos Estados Unidos. O agravamento da crise na integração andina aconteceu em 2006, quando a Venezuela denuncia o Acordo de Cartagena, retirando-se da CAN. O motivo alegado para saída venezuelana da instituição foi exatamente a assinatura de tratados bilaterais comerciais firmados por Lima e Bogotá com Washington. Outrossim, relembramos que membros remanescentes da CAN ficaram divididos em dois distintos projetos de integração: Bolívia e Equador ficaram associados à ALBA, enquanto Colômbia e Peru foram fundadores da Aliança do Pacífico. Ademais, na última década, a região andina assistiu tensos conflitos entre os países: rompimento de relações diplomáticas entre Equador e Colômbia após um bombardeio do governo de Bogotá a um acampamento de guerrilheiros em solo equatoriano; e houve ainda e estremecimento dos laços diplomáticos entre Bolívia e Peru, em razão do apoio peruano ao Chile na questão da pretensão de acesso boliviano ao Oceano Pacífico. ${ }^{46}$

\footnotetext{
${ }^{43}$ ESPINOSA, Maria. Mercedes, op. cit., p. 144.

${ }^{44}$ MORA, Luis Beltran, op. cit., p. 81.

${ }^{45}$ TAMAYO, Gustavo; MARTINEZ, Elias David. op. cit., p. 48.

${ }^{46}$ LUCIANO, Bruno; BRESSAN, Regiane, op.cit., p. 17.
} 
Em termos institucionais, retomamos o conceito de "overlapping' que se difundiu nas Relações Internacionais, principalmente nos estudos de regionalismo. Relembramos que esse conceito concerne ao fato de os países participarem concomitantemente de diferentes processos e projetos de integração, fazendo com que algumas dinâmicas se sobreponham integral ou parcialmente umas as outras. No caso andino, é nítida a superposição entre os mecanismos institucionais, dado que os países participam paralelamente de diferentes instituições e acordos (CAN, Aliança do Pacífico, ALADI, ALBA, entre outras). Esse overlapping ao mesmo tempo que sinaliza a busca contínua dos países da região pela cooperação, aponta também que os mecanismos criados ao longo das décadas não funcionaram adequadamente para que os países atingissem seus objetivos individuais. Assim, oportunamente, quando há possibilidade de ganhos materiais mais concretos, os países andinos têm optado por prevalecer seus interesses singulares, mesmo que isso possa significar o enfraquecimento da integração regional.

\section{Considerações finais}

No decurso dos anos de 1960 e 1970, o Pacto Andino, espelhado no modelo europeu, foi considerado um os mais avançados e exitosos da América Latina em termos de projetos de integração pelo grau de institucionalização atingido com a presença de órgãos supranacionais e intergovernamentais. ${ }^{47}$ No entanto, a partir da década de 1990, reverberam nos países andinos diferentes concepções de regionalismo. Desde então, chama a atenção a sobreposição de mecanismos de integração existentes na região andina: CAN, ALBA, Aliança do Pacífico, para citar os mais importantes atualmente. Possuindo perspectivas de entendimento distintas sobre os projetos da integração sub-regional e macrorregional, tais mecanismos findaram por colocar os países andinos em posições divergentes e contraditórias quanto aos rumos da própria integração entre eles. Em efeito, a região andina, devido às diversas dinâmicas concomitantes de integração, tornou-se um spagheti bowl,48em que encontramos tanto propostas paralelas de regionalismo (fechado, aberto e pós-hegemômico) quanto acordos mais centrados na dimensão econômica e outros pactos mais amplos, abrangendo distintas áreas: educação, saúde, política e cidadania.

\footnotetext{
${ }^{47}$ BRICEÑO-RUIZ, José; LOMBAERDE, Philippe. op. cit., p. 123.

${ }^{48}$ BHAGWATI, Jagdissh. US Trade Policy: the infactuation with FTAs, trabalho apresentado no encontro da Associação Econômica Americana, 1995, Washington.
} 
No campo teórico da integração regional, os autores discutem a hegemonia dos modelos explicativos europeus em detrimentos dos saberes produzidos em cada região numa espécie de colonização de conhecimento contra qual se deve combater. No entanto, é reconhecido que muitas dinâmicas e projetos de integração regional se inspiram no modelo europeu para se materializar e se institucionalizar. o contexto andino, numa análise de longo prazo, como sinalizado acima, foi e é palco de diferentes processos de integração que foram marcados por avanços, retrocessos, estagnações e mudanças de propósitos.

As possíveis explicações para os dilemas da integração andina são de diversas ordens e de níveis distintos de análise. No plano sistêmico, por exemplo, podemos relembrar as forças centrífugas (Estados Unidos, China e a União Europeia) que buscam estabelecer acordos preferenciais ou bilaterais de livre comércio com os países andinos, enfraquecendo, portanto, o ímpeto de aprofundamento da integração econômica intrabloco.

No nível intrarregional, destacamos a ausência de um país paymaster que assumisse o papel de líder da integração andina. Colômbia e Peru, as duas principais economias do bloco, jamais desempenharam essa função e, recentemente, optaram por acordos bilaterais extrabloco. Ademais, as recentes divergências políticas e diplomáticas entre os países são fatores desagregadores na atualidade da integração andina. A propósito, cumpre frisar que a Venezuela, outrora líder de um projeto de integração regional como a Alba, atualmente passa por processos de conflitos políticos internos e de acusações de violação de direitos humanos e de princípios democráticos. Sua situação política e humanitária é tão tensa e complexa que foi criado o Grupo de Lima, composto por países da região com disposição para colaborar com a retomada da democracia venezuelana. Nesses termos, é pouco provável que ela possa assumir um eventual papel de paymaster de uma retomada de projeto de integração andina.

Embora haja na atualidade riscos de uma possível desintegração regional andina, conforme assinalada por diversos autores, com seus membros divididos entre diversas instituições, blocos e alianças não se pode diminuir a importância dos projetos de integração andina como instigante objeto de estudo para os internacionalistas e politólogos.

Como últimas reflexões, aproveitamos o ensejo para reiterar que a existência de fatores externos, as constantes divergências internas entre os países andinos e a importação de diferentes modelos de regionalismos possam ser 
elementos explicativos para compreender os impasses históricos da regionalização andina. Esta, aliás, devido a estes aspectos empíricos mencionados, não se encaixa inteiramente em um único modelo explicativo já existente de integração. As especificidades, as divergências, os avanços e os retrocessos na integração na sub-região ainda desafiam os estudos mainstream da integração regional. Nesse sentido, futuras pesquisas devem refletir se efetivamente estamos vivenciando uma desintegração do regionalismo andino ou a regionalização andina é tão complexa que seria necessário um diálogo mais aprofundado entre um arcabouço teórico de integração regional já consolidado com um saber andino autóctone para se melhor compreendê-la?

\section{Referências}

BHAGWATI, Jagdissh. US Trade Policy: the infactuation with FTAs, trabalho apresentado no encontro da Associação Econômica Americana, 1995, Washington.

BRICEÑO-RUIZ, Jose. La integración regional en América Latina y el Caribe: procesos históricos y realidad comparada. Mérica: Universidad de los Andes, 2011.

BRICEÑO-RUIZ, José; LOMBAERDE, Philippe. Regionalismo latino-americano: produção do saber, criação e importação de teorias. Civitas, Dossiê Mundialização, regionalização e importação de teorias. Porto Alegre, 2018, p. 34-70.

ESPINOSA, Maria. Mercedes. La Comunidad Andina: las fuerzas centrífugas ejercidas por los Estados Unidos sobre un régimen comercial en formación. Desafios, 30, 135-172, 2018.

FAWCETT, Louise. The History and concept of regionalism. Trabalho apresentado na Conferência Bienal "Regionalismo e Lei Internacional”, Valencia, Espanha, 2012.

GAL, Paulo Henrique. Comunidade Andina de Nações e Aliança do Pacífico: modelos de integração regional. R.INDÉ de Ciências e Humanidade, São Bernardo do Campo, v.2, 2019, p.70-85.

GIARDINI, Gian Luca. The added value of The Pacific Alliance and modula regionalism in Latin America, LSE, International Affairs, 25 de junho de 2013, Disponível em http://tinyurl.com/y7vbo27h. Acesso em 20 de setembro 2019.

HERNÁNDEZ, Lorena. Evolución Institucional del Mercosur: construcción de capacidades regionales? Anais do XVI Congresso Internacional Fomerco, Salvador, Brasil, 2017. 
HURRELL, Andrew. O ressurgimento do regionalismo na Política Mundial. Contexto Internacional, Rio de Janeiro, vol. 17, n.1, 1995.

LUCIANO, Bruno; BRESSAN, Regiane A comunidade andina no século XXI: entre bolivarianos e a Aliança do Pacífico. Anais do XXXVIII Encontro Anual da ANPOCS, 2014.

MARIANO, Marcelo. A política externa brasileira e a integração regional: uma análise a partir do Mercosul. São Paulo: Editora Unesp, 2015.

MATTLI, Walter. The logic of regional integration: Europe and beyond. Cambridge University, 1999; MARIANO, Marcelo. A política externa brasileira e a integração regional: uma análise a partir do Mercosul. São Paulo: Editora Unesp, 2015.

MELO, Filipe Reis. ALBA-TCP. Un nuevo regionalismo lo más de lo mismo? In: OLIVEIRA, Renata; NOGUEIRA, Silvia; MELO, Filipe Reis. América Andina: integração regional, segurança e outros olhares. Campina Grande-PB: EDUEPB, 2012.

MORA, Luis Beltran. Comunidad Andina y negócios internacionales: uma visión desde su institucionalidad y supranacionalidad. Revista Escuela de Administración de Negocios, 75, p.70-85, 2013.

PAIKIN, Damián; PERROTTA, Daniella; PORCELLI, Emanual. Pensamiento latinoameicano para la integración. Crítica y Emancipación, p. 49-80,2016.

PANEBIANO, Massiano; VILLELA, Ana Maria. O grupo sub-regional andino. Revista de Informação Legislativa. Brasília. n.81, jan/março, 1984, p. 1-35.

PATRICIO, Ricardo (2014). América Latina frente à Globalização e à crise Econômica Global: a dispersão das respostas. In; SOUSA, Lara. (Coordenação). Crise, Estado e Segurança. Lisboa, MGI Editor, p. 271-294.

PERROTTA, Daniella. La integración regional como objeto de estúdio. De las teorias tradicionales a los enfoques actuales. Em: Elsa Llenderrozas, Teoria de las Relaciones Internacionales, EUDEBA, 2013, p. 1- 44.

POSE, Nicolás; BIZZOZERO, Lincoln. Regionalismo, Economía Política y Geopolítica: tensiones y desafios en la nueva búsqueda de inserción internacional del Mercosur, Revista Uruguaya de Ciência Política, 28, 2019.

PUERTAS, Jaime Acosta. La desintegración andina. Nueva Sociedad, 2006.

SENHORAS, Eloi. A dinâmica regional nas relações internacionais, Conjuntura Global, v. 4, n.3, 2015, p. 403-423. 
SÖDERBAUM, Fredrik. Rethinking Regionalism. Palgrave MacMillan, 2016; REGGIROZZI, Pía; TUSSIÊ, Diana. "Rethinking our region in a post-hegemonic moment”. In: BRICEÑO-RUIZ, José; MORALES, Isidro (orgs.). Post-hegemonic regionalism in the Americas. Toward a Pacific-Atlantic Divide? New York: Routledge, 2017.

SILVA, José Ultemar. A importância da Comunidade Andina para a economia da América Latina. Revista Gerenciais, São Paulo, v.5, n. 2, p. 72-81, 2006.

STEFANONI, Pablo. Posneoliberalismo cuesta arriba. Los modelos de Venezuela, Bolívia y Ecuador en debate. Nueva Sociedad, Buenos Aires, n. 239, maio-junho, 2012, Disponível em: http//: www.nuso.org.br. Acesso em 22 de outubro de 2019.

TAMAYO, Gustavo; MARTINEZ, Elias. La comunidad andina: cohesión interna e interesses individuales de los Estados miembros. Em: Renata Peixoto de Oliveira, Silvia Garcia Nogueira, Filipe Reis Melo. (orgs) América Andina: integração regional, segurança e outros olhares, EDUEPB, 2012.

TAMAYO, Gustavo; MARTINEZ, Elias David La comunidad andina: cohesión interna e interesses individuales de los Estados membros. In: OLIVEIRA, Renata; NOGUEIRA, Silvia; MELO, Filipe Reis. América Andina: integração regional, segurança e outros olhares. Campina Grande-PB: EDUEPB, 2012.

VEIGA, Pedro Mario; RÍOS, Sandra. O regionalismo pós-liberal, na América do Sul: origens, iniciativas e dilemas. Series CEPAL/Julho, 2007, p.7-47.

Artigo recebido para publicação em 02/01/2021 Artigo aprovado para publicação em 10/06/2021 